\title{
Revisiting December Hollow: Unearthing emotive shape
}

\author{
Milton Mermikides \\ University of Surrey \\ London, UK \\ m.mermikides@surrey.ac.uk
}

\author{
Peter Zinovieff \\ Unaffiliated \\ Cambridge, UK \\ peterz@zinovieff.com
}

\author{
Anne-Marie Curran-Cundy \\ University of Surrey \\ Guildford, UK \\ ac01618@surrey.ac.uk
}

\begin{abstract}
This paper documents an ongoing project between the composerlengineer Peter Zinovieff, composer Milton Mermikides and violinist Anne-Marie Curran-Cundy. The project is a developed realisation of Zinovieff's 1969 December Hollow 'fold-out score' concept. The compositional system is designed to generate electronic music and/or conventional scores by slicing through a three-dimensional topographical score of 'emotional zones'. Each zone is associated with a vector of musical parameters and by selecting various trajectories through the shape, countless pieces may be generated. This paper briefly outlines the approach taken to realize this idea, and develop it with the implementation of real-time processing, the mapping of score space with RGB space and vector transformations of Schumann's Mein Herz ist Schwer, within an adaptive performance model.
\end{abstract}

Generative music. Computer music. Graphic notation. Data music. Music and emotion.

\section{INTRODUCTION}

Among an eclectic collection of short stories, poems, artwork, film, art and book reviews, the $100^{\text {th }}$ issue of the London Magazine featured an essay titled The Special Case of Inspirational Computer Music Scores by the British engineer Peter Zinovieff (Zinovieff 1969). By the time of its publication, Zinovieff had earned a D.Phil in geology from Oxford University, researched audio processing at Bell Labs with Max Matthews and Jean-Claude Risset, established EMS and invented the VCS3 synthesizer, co-founded the electronic society Unit Delay Plus with Delia Derbyshire and Brian Hodgson and had built - around one of the UK's first personal computers - a home electronic studio in his shed in Putney (BBC 2019). This eclecticism is reflected in the essay, which touches on issues of conventional vs electronic music notation, generative and Artificial Life composition, novel human-machine interfaces and the employment of inventive strategies in the creation of formal 'emotional' musical structures. Through these musings, a new generative work December Hollow is sketched which adopts models from Zinovieff's geological and electronic experience and is capable of producing countless iterations.

While his subsequent career was highly productive and built on concepts presented in this essay, this particular idea was not able to be adopted technically with the primitive computer system available to him. However, a chance encounter in 2019, some 50 years later, with composer \& academic Milton Mermikides (University of Surrey, Royal College of Music), led to a revisiting of December Hollow. Mermikides's experience with data sonification and electronic music, allowed this concept to be reconsidered, supported by the affordances of contemporary technologies and the possibilities of real-time rendering and visualisation.

In addition to a geometric topographic approach, the 1969 essay also engages with a) a feedback loop between composer/listener and machine in the generational and b) the use of 'emotional parameters'. It was also decided to c) realise this project in a real-time performance, and so Doctoral researcher (in psychology and music) and violinist Anne-Marie Curran-Cundy joined and completed the project team.

\section{MODELLING DECEMBER HOLLOW}

The Special Case of Inspirational Computer Music Scores discusses the concept of computer notation and it's potential for the democratisation of musical parameters beyond - and between - the discrete, quantised pitch/rhythm/dynamic 'lattice' of standard notation (see Wishart 1996). It also considers the role such notation might play in the generation of effective music through the careful use of "controlled randomness" (Zinovieff 1969, p.170) in 


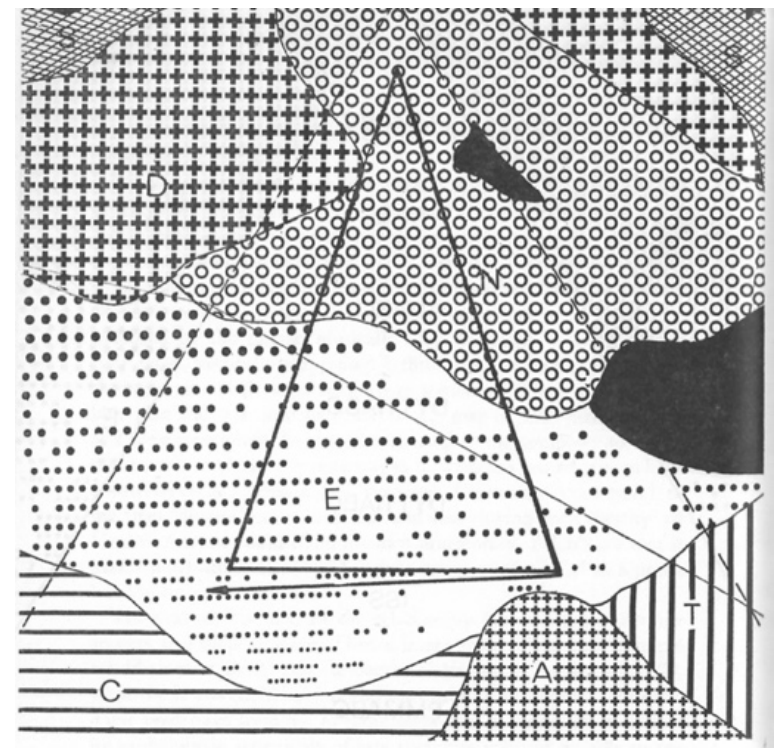

Figure 1: The 'emotional topography' of December Hollow (Zinovieff 1969, p. 173).

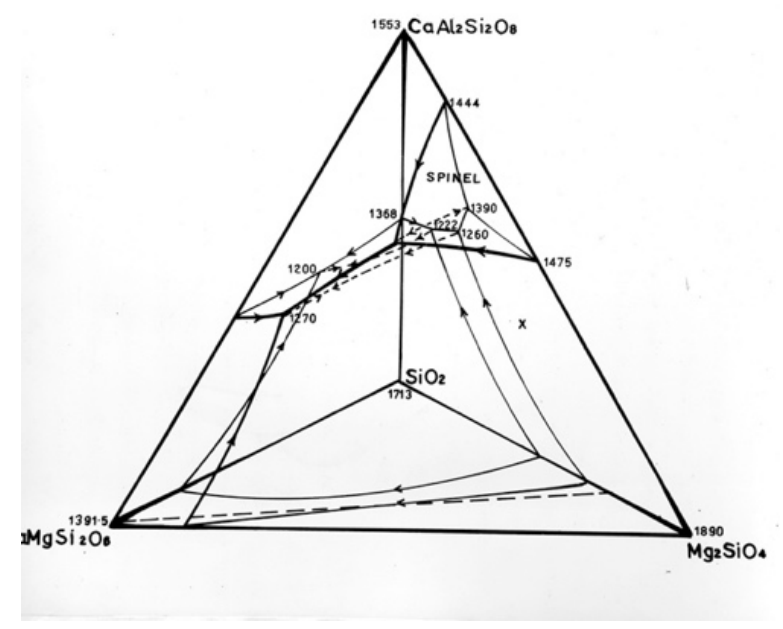

Figure 2: An image of the Silicon-Oxygen Tetrahedron with 'mineral zones' in Zinovieff's MIT thesis (Zinovieff 1963).

these parameters - a probability distribution across a range of musical processes. These 'probability musical vectors' are offered as a way of describing and means of conveying (or perhaps eliciting) emotions such as tension, catharsis, anxiety and so on. From these initial ideas, a novel "precompositional approach" is posited: a topography of musical/emotional states (such as Expectation, Tension, Neutrality) are drawn as variously shaded zones on a flat piece of paper (Figure 1). This score is folded into a 3-dimensional geometric shape - in this case an 'open tetrahedron' - hence 'December Hollow'. The shaded zones are hypothesised to continue through the structure, "like Brighton Rock" (Zinovieff 1969, p.172). By slicing this (or indeed any such) shape - with its mosaic of overlaid emotive states - 'emotional trajectories' through this topography are formed, generated countless electronic works from this limited resource. The computer reads through any such trajectory, and in another playful twist, asks the composer for feedback on its beauty, taking criticism and generating alternative realisations until the composer is satisfied.

Why quite such a visualisation is employed most probably stems from Zinovieff's background in the geological sciences (Figure 2), in its 'unearthing' of material and also the 'Silicon-Oxygen Tetrahedron' (see Marshak 2008, p.135-137), a neat representation of almost all silicates found in the Earth's crust. This particular representation also relates to Zinovieff's fascination with a) crossdisciplinary translations, b) 'complete' representations of musical possibilities, and c) the German musical term schwer, to mean a musical piece or passage that is 'heavy' or 'dense'.

Rather unsurprisingly, despite the clarity of this vision, Zinovieff's computer system at the time the $4 \mathrm{~K} \mathrm{PDP} 8 / \mathrm{s}$ programmed with punch cards to control the oscillators and amplifiers of his synthesizer could not realise the project and it was suspended for 50 years, when Zinovieff met Milton Mermikides at a lecture at the University of Surrey in 2019.

\section{REALISATION}

Mermikides's experience and interest in data sonification (in his 'hidden music' series), complete multi-dimensional visualisations of musical parameters (Figure 3) and computer music programming (Mermikides 2011, Dean 2011 p.446-450, Mermikides \& Feygelson 2018) helped realise the project.

A tetrahedron was rendered in MAX/MSP Jitter, and populated with the shaded zones (Figure 4). This object may be visually rotated and sliced to produce a large number of $2 \mathrm{D}$ maps, from which one can be selected, and a trajectory through it can be executed. In order to associate musical transformations to these zones, Schumann's Mein Herz ist Schwer was used as a dense material rich in transformative possibilities.

The score was converted to MIDI, and a bank of phrases was collated for automated playback and transformation. Parameters such as velocity, relative duration, density, pitch multiplication, elements of timbre, register, temperament and spatialisation formed a 'musical vector'. Each zone not only represented a value for each of these values, but a probability distribution for each parameter (Boredom, for example would have no deviation from a specific pitch multiplier, while Anxiety would contain a wide standard deviation of velocity). 


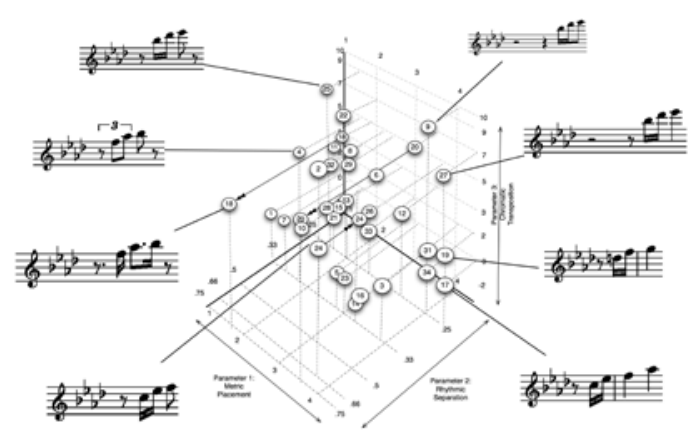

Figure 3: An example of Mermikides's ' $M$-Space' modelling of musical parameters: a John Coltrane improvisation plotted in the three-dimensional musical space of metric placement, rhythmic separation and chromatic transposition, (Mermikides 2011, p.26).

These vectors could be modified at any point even during performance, and the zones reassigned to any vector.

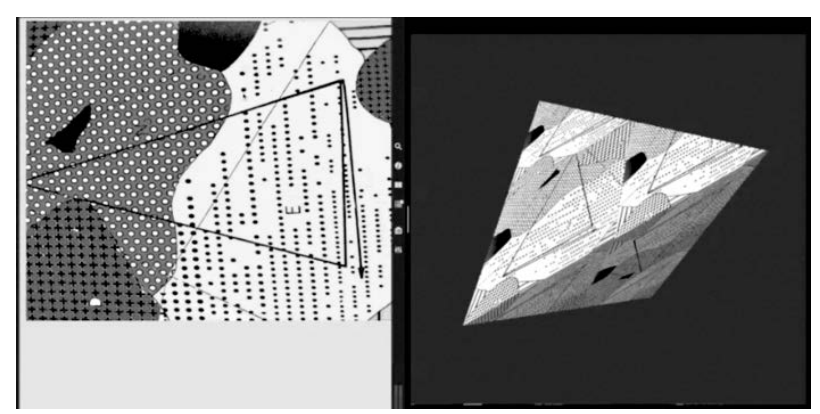

Figure 4: Max/MSP realisation of the December Hollow tetrahedron (right), with a selected trajectory (left).

A trajectory would thus trigger a transformative interpretation of the musical material based on the 'zone' of the moment. Some trajectories might occupy just a couple of moods; others might deliver a rapidly changing emotional landscape.

\section{PERFORMANCE MODEL}

While this approach revealed some perceptible and satisfying results, it lacked the human/machine interplay of the original idea, and the aims of creating a performable work were not yet met.

Relaying similar musical materials for CurranCundy, the violinist to also play felt redundant, and a doubling of duties, improvising 'whatever' on the other hand felt too uncontrolled and arbitrary.

To create some sense of performance, an interaction with the machine, and a sense of the emotional engagement, selected notated cells of the zones are relayed to her, and she was also given some rudimentary controls (operated by a MIDI foot controller). These allow slow steering, breaking and accelerating, modifying the trajectory as the mood takes her. She is able to come to a near stand still, avoid zones or rush through them in serious 'mood swings'. This small adjustment, had a significant sense of engagement with the piece and the zones, and sense of 'travel'.

\section{COLOURING EMOTION}

An issue with the model as it stood is at the boundary points, vectors would jump immediately or be subject to a mechanical transition. However, a previous device created by Mermikides, Kandinsky (Figure 5) was employed to address this. Kandinsky is able to carve similar trajectories across any digital image (or video), reporting on colour data at controllably regular intervals (BBC 2018), interpreting them in terms of colour scale, or controller data, allowing the user to listening to any work of art, the subtle shades of Monet, the hardedged but asymmetrical rhythms of a Bridget Riley. This is now replacing the abstract and discrete shading of December Hollow. Now a specific zone can be represented by a specific colour (a point in 3D RGB space). This allows the tetrahedron to be filled not just with hard edges but soft blurring between these points. Each parameter of the vector interpolating in sympathy with its colour coordinates. When filling the tetrahedron with variously overlapping and 'marbled' coloured zones, produces more complex and subtle transitions and interstitial 'moods' even with a limited number of initial zones. Together with the 'soft guidance' performance system, and an LED light system projecting 'colour of the moment' during the performance, this feels to the authors as both meeting and enhancing the spirit of the essay, on its semi-centennial anniversary.

\section{REFERENCES}

BBC (2018)

https://www.bbc.co.uk/programmes/b0bgfax7 (retrieved 19 March 2020).

Dean, R. (ed) (2011) The Oxford Handbook of Computer Music. 1st Edition. Oxford University Press, Oxford.

Marshak, S. (2008) Earth: Portrait of a Planet. Norton \& Company, New York.

Mermikides, M. (2011) Changes Over Time: Theory and Practice. PhD Thesis, University of Surrey.

Mermikides, M. and Feygelson, E. (2018) The shape of musical improvisation. In Music and Shape, Oxford University Press, Oxford.

Wishart, T. (1996) On Sonic Art. Harwood Academic Publishers, Amsterdam.

Zinovieff, P. (1958) The basic layered intrusion and the associated igneous rocks of the Central and Eastern Cuillin Hills, Isle of Skye. D.Phil Thesis, Oxford University.

Zinovieff, P. (1969) The Special Case of Inspiration Computer Music Scores. London Magazine, 100, 165176. 


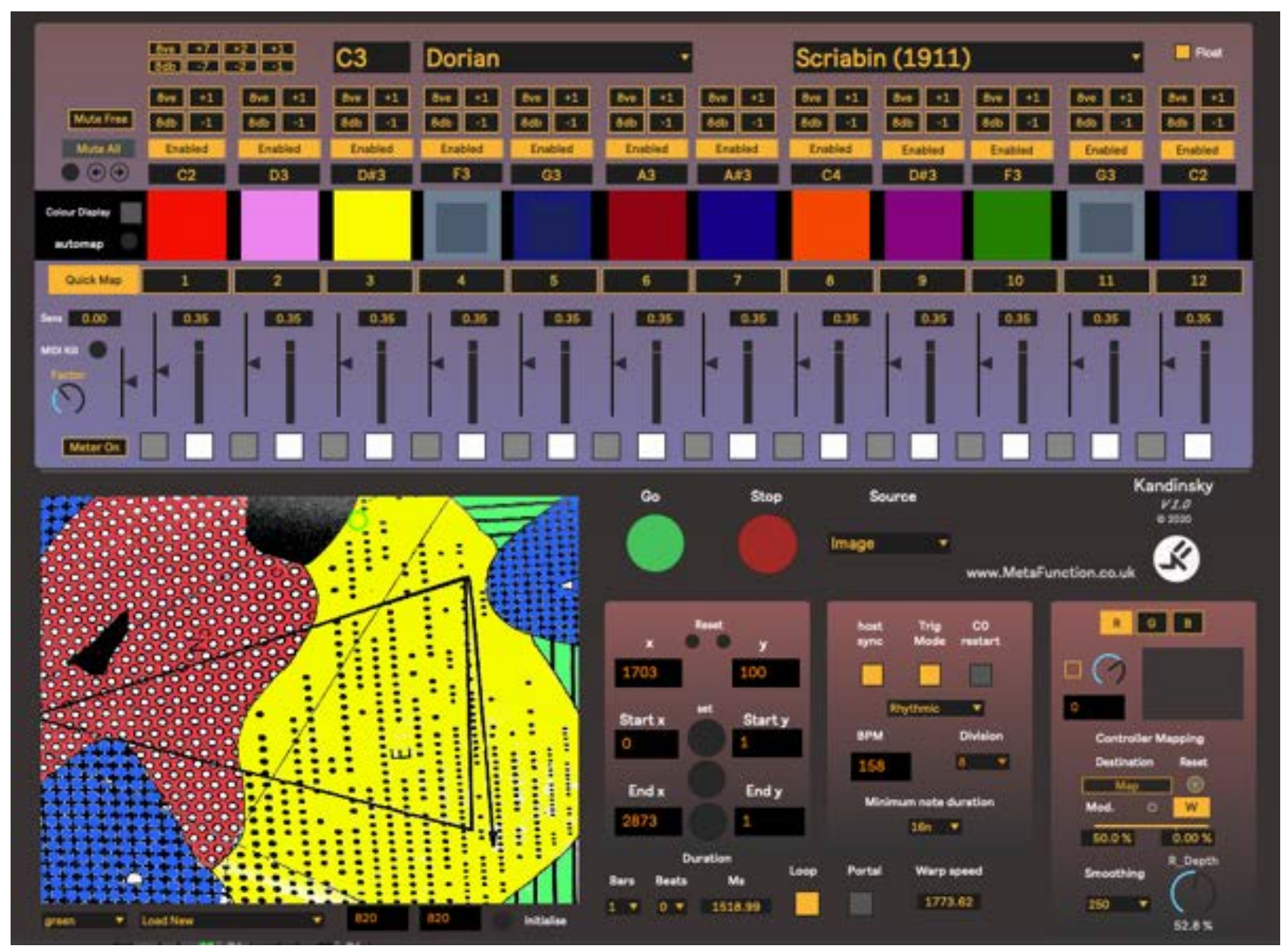

Figure 5: Kandinsky, a MAX/MSP device used to translate RGB colour data in images to note, velocity and continuous controller data, now employed in December Hollow 2020. 